\title{
Qualitative analysis of impact of congenital hand differences on children visiting a tertiary care hospital
}

\author{
Divine Thampi ${ }^{\mathrm{a}}$, Anil K. Bhat ${ }^{\mathrm{b}}$, Arathi P. Rao ${ }^{\mathrm{a}, *}$, Navya Vyas ${ }^{\mathrm{a}}$, Manisha Gore ${ }^{\mathrm{c}}$ \\ a Prasanna School of Public Health, Manipal Academy of Higher Education, Manipal, India \\ ${ }^{\mathrm{b}}$ Department of Orthopaedics, Manipal Academy of Higher Education, Manipal, India \\ ${ }^{\mathrm{c}}$ Faculty of Health and Biological Sciences, Symbiosis International University, Pune, India
}

\section{A R T I C L E I N F O}

\section{Keywords:}

Congenital hand differences

Quality of life

Coping

Qualitative study

Stigma

Impact of surgery

\begin{abstract}
A B S T R A C T
Congenital hand differences (CHD), being a visible deficiency, has immense negative influence on the physical, psychological and social wellbeing of a child.

Purpose: The children and their mothers were given an opportunity to express their perspectives about the disability and its impact on the daily life of the child.

Method: OLOGY: 12 children (6-15 years) and their mothers were enrolled between January to June 2017. Indepth interviews were conducted to know the experiences and perspectives of children with congenital hand differences and their mothers. Transcribed verbatim of interviews were analyzed by manual coding followed by thematic analysis.

Results: Children expressed that they performed most of their daily activities with partial or minimal involvement of their parents. They exercised a certain degree of independence in meeting their self-care needs by adapting to the disability and reported that they were cared and supported by family members. Although these children encountered stigma from society, they were able to cope with the situation by accepting their disability with positive support from their parents. Majority of mothers and children reported that the surgical intervention has improved the physical functioning of hand. All the participants reported that they did not depend on any orthosis for daily activities. The orthosis provided were only to retain the correction of their deformities and was used mostly as a night splint.

Conclusion: Children with congenital hand differences were capable of independent living and showed positive coping towards the societal stigma. Surgical treatment has improved the function and confidence of their children as stated by their mothers.
\end{abstract}

\section{Introduction}

Congenital hand differences (CHD) are conditions resulting from failure of transformation of arm bud cells to upper limb in a programmed manner. This contributes to long-term disability in children in terms of limited hand function and poor aesthetic appearance $e^{1,2,3}$ It accounts for $10 \%$ of all congenital abnormalities ${ }^{4,5}$ Research has been conducted globally in relation to the magnitude of the problem, classification of congenital hand differences and treatment modalities but studies are insufficient to address the quality of life of children with hand differences ${ }^{6,7}$

Although these congenital hand differences are not so common, they have great influence on the child's physical, mental and social functioning categorized as health related quality of life. The World
Health Organization defines health related quality of life as an individual's perception of their position of life in the context of culture and value systems in which they live, and in relation to their goals, expectations, and concerns. ${ }^{8}$ Since the quality of life is subjective in nature, children need to be encouraged to self-report their experiences and perspectives whenever possible, even though the parents perspectives can be a counterbalance ${ }^{9,10}$

Information regarding substantial difficulties faced by children with hand differences in the execution of daily tasks and involvement in school and extracurricular activities are minimally known. ${ }^{6,11}$ However, environmental factors which include the individual's family environment and society have greater impact on individual's functioning and disability. ${ }^{12}$ Most children with hand deformity generally receive medical care and treatment which helps in function and aesthetics since

\footnotetext{
* Corresponding author. Prasanna School of Public Health, Old TAPMI Building, II floor, Manipal Academy of Higher Education, Manipal, 576104, Udupi, Karnataka, India.

E-mail address: arathimph@gmail.com (A.P. Rao).
} 
it is a visible defect. ${ }^{13}$

We explored the experiences and perspectives of children with congenital hand differences and their mothers through various domains such as its impact on daily activities, school life, family functioning and dynamics, social experiences as well as child's perceptions about self, surgery and treatments.

\section{Methodology}

The present study was conducted between January to June 2017 in a tertiary referral center for Karnataka and neighboring state, Kerala and is the only well-equipped department in the district. The hospital statistics showed that around 253 cases of CHD had consulted the department for specialized treatment between 2000 and 2016. Radial club hand and syndactyly were the most common conditions seen during this period.

12 children of 6-15 years with hand anomalies were included in the study and the sampling strategy adopted was purposive sampling. Among them three cases were diagnosed of radial club hand, two cases of syndactyly, rest were cases of phocomelia, bilateral clasped thumb, symbrachydactyly, congenital amputation, constriction band syndrome, trigger thumb, bilateral absent thumb and clinodactyly. Those with a history of mental disorder or developmental delay and those with multiple anomalies were excluded. Eight mothers of 8 children who participated in the study were included in the study. Participants were from different districts of Karnataka and Kerala states who were either attending orthopedic outpatient department or admitted at the Hospital. KMC/KH Institutional Ethical clearance (IEC No- 885/2016) was obtained prior to the commencement of the study.

Phenomenological approach was used in this qualitative study to assess the impact of congenital hand differences on the quality of life of children by exploring their experiences and perspectives including their mothers. A phenomenology is a qualitative research method that describes experience of a certain phenomenon as described by the person. Epistemologically, phenomenological approaches are powerful for understanding subjective experience, gaining insights into people's motivations and actions, which was essential to understand subjective experiences of respondents' with rare congenital deformity and their care takers so this approach was used in this study. ${ }^{14}$ Two different validated interview guides were used for children and mothers. The interview guide was designed under the domains of day to day activity, school functioning, physical health, psychological health, family relationship, social interaction, spiritual and personal belief, health care and treatment, impact of surgery and rehabilitation care. Confidentiality of the patient information was maintained throughout the study.

Assent and written informed consent were obtained from children and their mothers respectively for interviews and audio recording of interviews were done. Transcripts were prepared from audio records. Data saturation was achieved and manual coding was done following translation. Inductive approach for data analysis was adopted for the explorative study design. The frequently reported patterns; number of respondents expressing similar responses were pulled together under respective codes. The analysis was restricted till coding phase only. Only one researcher with expertise in qualitative analysis performed the coding.

The codes were grouped into categories to identify major themes from the content that describes the impact of congenital hand differences on the quality of life of the affected children.

\section{Results}

12 children with CHD and their mothers participated in this qualitative study. The background data of the children is shown in Table 1.
Table 1

Summary of the Socio-demographic data of the children.

\begin{tabular}{|c|c|c|c|}
\hline & Range & Frequency (n) & Percentage (\%) \\
\hline \multirow[t]{3}{*}{ Age (Years) } & $6-10$ & 7 & $58 \%$ \\
\hline & $11-15$ & 5 & $42 \%$ \\
\hline & Total & 12 & \\
\hline \multirow[t]{2}{*}{ Gender } & Male & 6 & $50 \%$ \\
\hline & Female & 6 & $50 \%$ \\
\hline \multirow[t]{9}{*}{ Diagnosis } & Radial Club Hand & 3 & $25 \%$ \\
\hline & Syndactyly & 2 & $17 \%$ \\
\hline & Phocomelia & 1 & $8 \%$ \\
\hline & Bilateral Clasp thump & 1 & $8 \%$ \\
\hline & Symbrachydactyly & 1 & $8 \%$ \\
\hline & congenital amputation & 1 & $8 \%$ \\
\hline & $\begin{array}{l}\text { Constriction band } \\
\text { syndrome }\end{array}$ & 1 & $8 \%$ \\
\hline & Trigger thumb & 1 & $8 \%$ \\
\hline & Bilateral clinodactyly & 1 & $8 \%$ \\
\hline \multirow[t]{9}{*}{ Place of residence } & Udupi Taluk & 4 & $33 \%$ \\
\hline & Kundapur Taluk & 1 & $8 \%$ \\
\hline & Karkala Taluk & 3 & $30 \%$ \\
\hline & Byndoor village & 1 & $8 \%$ \\
\hline & Davangere district & 1 & $8 \%$ \\
\hline & Total (Karnataka) & 10 & $83 \%$ \\
\hline & Palakkad district & 1 & $9 \%$ \\
\hline & Thrissur district & 1 & $9 \%$ \\
\hline & Total (Kerala) & 2 & $17 \%$ \\
\hline
\end{tabular}

\subsection{Degree of dependence of children}

Most mothers reported that their children were minimally or partially dependent on parents, friends and teachers and they seek their help only for specific activities which they could not perform due to their disability.Speaking about her son with radial longitudinal deficiency, a mother said that he found it very difficult wringing a bath towel or to tie his shoe laces. Nearly half of the total children reported that they help themselves in their basic needs but they depended on their parents partially especially for washroom activities (Table 2) Children self-reported that they performed activities with minimal support of disabled hand and maximum use of normal hand.

The mothers also reported that the children took part in games and sports with support and encouragement from parents and teachers and adapted especially as they grew older. Mothers facilitated their sporting activities by providing favorable and convenient play accessories. Some mothers said that the children were active and interested in exploring their skills and attempted to play like others (Table 2).

\subsection{Impact on family}

Mothers opined that healthy siblings assisted and supported their siblings with anomaly. Children self-reported that their siblings assisted in the activities or in physical needs and took care of them when they were injured. "When I have to carry the school bag, if it is too heavy, my younger brother carries it for me on the way to school" (14 year old boy with left radial longitudinal deficiency) Children tend to imitate their siblings and attempt to become independent in self-care activities and play. A mother stated that her daughter with anomaly ate independently and brushed on her own imitating her brothers.

Most mothers felt that the family members and relatives had overcome the initial shock and have started accepting and loving the child, despite the child being different. A mother shared her experience about her husband's perception and how he changed gradually quoting "When my daughter was very small my husband was so negative, he would not even look at the face of his own daughter. Now the father and daughter are very good friends." (Mother of 14 year old girl with bilateral radial longitudinal deficiency) Children self-reported that family members love them and meet their daily requirements and desires. "My parents talk to me with great love"(8 year old girl with 
Table 2

Representative quotations.

Degree of dependence of children

- "She is habituated to do work with normal hand. She does things on her own like tying her hair, wearing her clothes, button, belt and all other chores. Even in the toilet she is independent though her hand is weak" (Mother of 8year child with congenital transverse deficiency below elbow)

- . "I play cricket with a small bat as the big bat is too difficult for me to score runs" (10 year old child with left radial longitudinal deficiency)

- "When my daughter falls, she always has swelling on her face because she can't fall on her hands like us because her hands are weak, so her forehead directly hits the floor"(Mother of 14 year child with bilateral radial longitudinal deficiency)

- "I can't hold bicycle handle with my fingers in one hand, so I just support it by placing it in my curved forearm"(14 year child,left radial longitudinal deficiency)

- "She is very smart in everything, she does cycling on the road though her one hand is of no use. (Mother of 8 year child with congenital transverse deficiency at proximal arm)

Impact on family

- My father-in-law always nagged saying that my girl child was disabled and hence no marriage was possible for her. Later he changed, when he found me requesting my sons to supervise the marriage of their sister and perform it with all grandeurin future. My father-in-law got the message and there was complete change in him.(Mother of 14 year old child with bilateral radial longitudinal deficiency)

- My Grandma takes me for walks and father takes me in bike. I feel happy when I go with them" (8 year old girl with congenital transverse deficiency below elbow).

- "When I have a fall, my brother takes me home and applies pain relieving ointment" ( 9 year old boy with bilateral clasped thumb)

Social system and its impact

- "She won prizes in all competitions like fancy dress, singing, story-telling, drawing, elocution. My daughter is fearless on stage. She attends bharthanatyam(Indian classical dance) class in the school after regular school hours. She performs well and we encourage her in every way". (Mother of 8 year old child with congenital transverse deficiency below elbow)

- Teachers are always concerned about my hands so they instruct other children to allow me to sit in the left corner of bench(14 year child with left radial longitudinal deficiency)

- "Teachers say bye to me, they love me and in the class they ask me if I have pain or if I am ok. They ask me about the likely marks I will be getting in my exams. I am very happy with my teachers" (11year old child, Symbrachydactyly)

- " I can't open my tiffin box because it is big and I can't get a grip, then my friends help me" (8year old child, congenital transverse deficiency below elbow).

- "They said you are not needed as your hand is not proper and so don't come for play". (9 year old child with bilateral clasped thumb)

Coping strategies of children

"God ...please split the fingers of both my hands"(14 year old girl child with bilateral syndactyly)

"When some children ask my daughter what is this problem in your hand, she replies it is nothing but 'vavu'(meaning mild illness in local language.)" (Mother of 14 year old child with syndactyly)

Effect of Health care and treatment

- "I am scared, if it will be painful when the doctor separates fingers during operation. After the surgery would the hand be proper to write and will it be easy to hold things? Will I be able to wear finger rings and apply mehendi (traditional hand art) also?" (14 year old girl with syndactyly.)

- "When my daughter had a surgery she was shifted to the post-operative ward and the doctor visited her despite of the fact that he had no rest at all and it was quite late." (Mother of 14 years old girl with syndactyly)

congenital transverse deficiency at proximal arm).

\subsection{Social system and children with congenital hand differences}

Mothers shared that teachers supported and rendered special care to their children. A mother reported that his teacher advised about the child's treatment and gave valuable suggestions "Teacher suggested to get the surgery done as advised. She said there was no problem if he took leave of one month to undergo the surgery." (Mother of 9 year old child with bilateral clasped thumb deformity) Mothers reported that their teachers assisted in their children's self-care needs. They advised the parents to train their child to be independent and counseled mothers to nurture self confidence in children. Children self-reported that teachers cared and supported them and admonished other children who made fun of them. More than half of the total children with differences stated that equal opportunities were given by teachers to them in class room activities.

Mother and children reported positive and negative experiences with friends. On the positive note, class mates were supportive, understanding, and considered them like normal children. A mother revealed that her child was assisted in self-care needs by her close friend. "Her close friend helps her to wear undergarments after using the toilet (mother of child with 14 year old with bilateral radial longitudinal deficiency) Children stated that their friends were very cooperative and assisted them in class work. A child shared his experience about going on a for tour with his friends, visiting different places and sharing snacks with each other and this experience gave him great happiness.

On a negative note, a mother shared that some of her child's friends had made so much fun of the anomalies and the child was very upset. They finally had to change the school. "When he was in primary school, his classmates cracked jokes about him saying that his hand looks like the trunk of an elephant. (Mother of 14 year old child with left radial longitudinal deficiency)Another child self-reported that his friends had neglected him and didn't involve him in games due to his hand anomaly.

The children were encouraged by their mothers to attend social activities with friends as they felt that their children despite their limitation, deserved to be like their peers. A mother claimed that if her child met new people, the child is interested to introduce himself/ herself to others and add them in friends' list on social medias, irrespective of their age. Mothers reported that their grandparents, relatives and neighbours liked their children. They interacted well with all relatives and assisted them in various activities. When my daughter was in her grandma's house she was very helpful to my mother and involved herself in simple household chores (Mother of 8 year old girl with congenital transverse deficiency at proximal arm).

A mother opined that at family functions ladies would stare at her son and comment about him. They would examine the hands of her son and ask many questions about treatment, surgery etc. One third of the parents were forced to bring their child for surgical correction prompted by negative comments from relatives and neighbours. "The fingers have to be separated to stop the comments and laughter of neighbours and relatives. They make fun of me, saying that I may need a very big finger ring for my marriage as my fingers are joined". (14 year old girl with syndactyly).

Majority of the mothers reported to have received financial assistance for the child's disability from the Government. Some religious trust and political leaders provide them with financial help also. A mother reported that the local Government body allocates funds for disabled children and their caregivers and are very active in empowering disabled children.

\subsection{Coping strategies of children}

Mothers reported that their children knew how to cope positively and to answer their classmates' queries because of parents' psychological support. A mother stated that both children and mothers attended a day out organized exclusively for disabled children and their mothers by the local Government body because they felt comfortable compared to other social functions where people observe them and comment on them.

A mother stated that even though the child remained self-dependent 
and active he felt sad seeing his younger brother riding a scooter which he couldn't do. A few affected children did not want to reveal that they were partially dependent on their siblings. So, when a mother revealed that the child's brother had assists the disabled child in putting on his dress, the child was unhappy about sharing that information. According to some mothers their affected children always had queries about their hand structure and aesthetics. A mother shared that her daughter with hand anomaly likes to use nail paint very much and would love to paint her nails.

Both mothers and children shared that they visited pilgrimage centers and religious places to get blessings for betterment of health. Few of the children self-reported that they prayed to God regularly to heal their anomaly. "I join hands in front of God to keep me healthy and make my hands proper" (9 year old boy with bilateral clasped thumb).

\subsection{Effect of health care and treatment}

Mothers shared that children had no reservations to go to the hospital and get admitted since they had experienced positive outcomes from the treatment. Majority of children talked about their dreams and stated that they were optimistic about their future. "I very much desire to become an engineer. I have keen interest in repairing things at home and have self-confidence that if my hand gets better I hope to fulfill my dream"(9 year old boy with left radial longitudinal hand deficiency).

They have a good opinion about the health care team and quality of care from the hospital. A mother shared her view that her child is fond of her treating doctor in the following words "She likes doctor uncle a lot" (Mother of 14 years old girl with syndactyly).

More than half of the mothers who participated in the study reported that their children had undergone surgeries at a young age, hence were unaware of it and opined that surgical intervention had improved the child's hand functioning and activity level. A child's selfreport on post-surgical improvement was ".After surgery, I felt happy because my hand had become almost a normal hand. Now I can hold the phone, I can lift bottle with this hand. Previously, I could hardly hold a paper with my affected hand" (10 year old boy with left radial longitudinal deficiency).

A mother explained that her child had rejected the prosthesis as movements were restricted. She preferred to do all activities without prosthesis. "My daughter declined the artificial hand as she wanted free movement to do things with her affected hand" (Mother of 8 year old girl with congenital transverse deficiency below elbow). Another mother reported that her child refused to wear the splint given by the occupational therapy department as the child experienced pain and discomfort after wearing it. Table 2 represents the verbatim of the study participants in detail.

\section{Discussion}

This study shows that children with CHD make attempts to lead a normal life. Children were habituated to perform activities with affected limb and were actively involved in their day to day activities at home and school including sports and various competition. The phenomena of being independent and self-confident with advancement of age were noticed among these children. Children experience only minimal limitation in day to day activities and there are no situations where participation of these children is impossible. Limitations experienced by children could pertain to only environmental factors like people who lack knowledge of the child's capacities. ${ }^{15}$ This was reflected in our study with instances in children's life where friends made false judgments about their capabilities and ignored them during play because of their anomaly.

Another major reason for limited participation during play by these affected children was restrictions posed by corrective device or prosthesis. ${ }^{15,16}$ In our study, a mother has opined that her child had rejected the prosthesis since the movement was restricted and the child preferred to do activities without the prosthesis.

Children with less affected digits have higher emotional imbalance where as children with too severe a disability accept the fact that they cannot have a normal hand and they are emotionally resigned. ${ }^{17,18}$ Our study could found similar emotional reactions. The self-report of a child with severe disability was that she used only one hand to grip the bicycle handle as she considered the affected limb to be of no use at all.

Mothers have important role in emotionally strengthening and building self confidence in children with CHD. Children are educated by parents to adjust with peers who sometimes engage in misbehavior such as teasing. ${ }^{19}$ Mothers do agree that children with congenital hand differences may have to encounter teasing from friends and society in their day to day social life. Hence it is necessary to train and develop positive thinking in children convincing them that the differences are acceptable which they have since birth. Mothers positive thinking and coping can have a reflection in child's social life.

Mothers of children with hand differences were concerned about their education, health, future of their children, career and independence. However, many parents believed that mainstream school was the appropriate way to succeed in society but some were scared that their children would be extremely different from their peers in such school. ${ }^{20}$ The finding of the present study showed almost all mothers were pleased with the current performance and achievements of their children. All the participant children with various hand differences belonged to mainstream school.

Few studies have highlighted that teachers had shown poor performance report of affected children to their parents and criticized them for the same. ${ }^{21,22}$ The result of the present study shows that teachers were very supportive, motivating and impartial to the children with hand differences. They provided guidance to parents to train and educate the children to independently perform their activities and to build their self-confidence. In addition to that, teachers encouraged parents to seek specialized treatment and facilities for their child.

Few studies have shown that parents were anxious when they left their child with their friends. ${ }^{22,23}$ Most often parents have a tendency to be overprotective of their children. ${ }^{20}$ Our study shows children were given the freedom to move around with other children, play and attend functions. Mothers believed that though children were affected they also deserve independence and normal social life like other children.

Connecting parents of children with CHD can help them to be aware of the various community programs suitable for their children. ${ }^{22,24}$ In our study mothers who had the experience of the day out organized by local Government bodies for disabled children opined that this gave an opportunity to talk and interact with the mothers of children with different disabilities. They felt a sense of belongingness when both mothers and children interacted with each other creating a very positive environment. Social networking among parents of children with differences gave them an opportunity to learn from each other about the coping strategies.

\subsection{Limitations}

The present study is conducted in a hospital based setting and hence the findings has to be generalized based on the context. The sample is representative of the patients seeking care in a tertiary care hospital and might not be representative of the community. Coding of the data was done by a single coder in the present study.

\section{Conclusion}

Children with congenital hand differences who received treatment were relatively independent and were able to cope with the daily challenges, even though they received negative responses from friends, relatives, and society at times. Most often parents and teachers were the ones who provided support and confidence for the children to overcome 
such situations. Surgical interventions also had a major role in the quality of life of these children, thereby creating a hope for the families. However, school and community based programs are required in a big way to promote awareness and enhance the acceptability of children with congenital hand differences in society.

\section{References}

1. Oberg KC, Feenstra JM, Manske PR, Tonkin MA. Developmental biology and classification of congenital differences of the hand and upper extremity. $J$ Hand Surg Am. 2010;35(12):2066-2076.

2. Tonkin MA, Tolerton SK, Quick TJ, et al. Classification of congenital differences of the hand and upper limb: development and assessment of a new system. J Hand Surg Am. 2013;38(9):1845-1853.

3. Peng H, Wang X, Duan Y, Frey SH, Gu X, Brook S. HHS Public Access. 2016:84-91.

4. Flatt AE. Classification and Incidence. The Care of Congenital Hand Anomalies. 1994; 1994:47-63.

5. McCarroll HR. Congenital anomalies: a 25-year overview. J Hand Surg. 2000;25:1007-1037.

6. Kelley BP, Franzblau LE, Chung KC, Carlozzi N, Waljee JF. Hand function and appearance following reconstruction for congenital hand differences: a qualitative analysis of children and parents. [Internet]. Plast Reconstr Surg. 2016;138(1):73e-81e. Available from: http://www.ncbi.nlm.nih.gov/pubmed/ 273486.

7. Giele H, Giele C, Bower C, Allison M. The incidence and epidemiology of congenital upper limb anomalies: a total population study. J Hand Surg Am 2001;26(4):628-634.

8. World Health Organization Division of Mental Health. Measurement of Quality of Life in Children. Geneva: World Health Organization; 1993.

9. Ardon MS, Janssen WG, Hovius SE, Stam HJ, Selles RW. Low impact of congenital hand differences on health-related quality of life. Arch Phys Med Rehabil [Internet]. 2012;93(2):351-357. Available from: https://doi.org/10.1016/j.apmr.2011.09.004.

10. Sheffler LC, Hanley C, Bagley A, Molitor F, James MA. Comparison of self-reports and parent proxy-reports of function and quality of life of children with below-the-elbow deficiency. J Bone Jt Surgery-American. 2009;91(12):2852-2859 [Internet].
11. Ho ES, Clarke HM. Upper extremity function in children with congenital hand anomalies. $J$ Hand Ther. 2005;18:352-364.

12. WHO. International Classification of Functioning, Disability and Health (ICF). Geneva: World Health Organization; 2001.

13. Watson S. Current topic: the principles of management of congenital anomalies of the upper limb. Arch Dis Child. 2000;83(1):10-17.

14. Creswell JW, Poth CN. Qualitative Enquiry and Research Design, Choosing Among Five Approaches. second ed. SAGEPublication: United States of America; 1997:57.

15. De Jong IGM, Reinders-Messelink HA, Tates K, et al. Activity and Participation of children and adolescents with Unilateral Congenital below Elbow Deficiency : an online focus group study. J Rehabil Med. 2012;44(10):885-892.

16. James MA, Bagley AM, Brasington K, Lutz C, McConnell S, Molitor F. Impact of prosthesis on function and quality of life for children with unilateral congenital below-the-elbow deficiency. J Bone Joint Surg. 2006;88A(11):2356-2365.

17. Andersson G-B, Gillberg C, Fernell E, Johansson M, Nachemson A. Children with surgically corrected hand deformities and upper limb deficiencies: self-concept and psychological well-being. J Hand Surg. 2001;36(9):795-801.

18. Ardon MS, Janssen WG, Hovius SE, Stam HJ, Selles RW. Low impact of congenital hand differences on health-related quality of life". Arch Phys Med Rehabil[Online]. 2012;93(2):351. https://doi.org/10.1016/j.apmr.2011.09.004.html Availablefrom: Accessed date: 30 August 2017.

19. Bedell GM, Cohn ES, Dumas HM. Exploring parents' use of strategies to promote social participation of school-age children with acquired brain injuries. Am J Occup Ther. 2005;59(3):273-284.

20. Antle BJ, Mills W, Steele C, Kalnins I, Rossen B. An exploratory study of parents' approaches to health promotion in families of adolescents with physical disabilities. Child Care Health Dev. 2007;34(2):185-193.

21. Vogts N, Mackey AH, Ameratunga S, Stott NS. Parent-perceived barriers to participation in children and adolescents with cerebral palsy. J Paediatr Child Health. 2010;46(11):680-685.

22. Heah T, Case T, McGuire B, Law M.Successful participation: the lived experience among children with disabilities, Vol 74 no 1 pp 38-47.

23. Missiuna C, Moll S, King S, King G, Law M. A trajectory of troubles: parents' impressions of the impact of developmental coordination disorder. Phys Occup Ther Pediatr. 2007;27(1):81-101.

24. Huang Y-P, Kellett U, St John W: Being Concerned: Caregiving for Taiwanese Mothers of a Child with Cerebral Palsy. 